\title{
Differential Pulse Voltammetric Determination of Paracetamol Using Activated Glassy Carbon Electrode
}

\author{
Meselu Eskezia ${ }^{* 1}$, Dereje Yenealem ${ }^{2}$ \\ ${ }^{l}$ Department of Chemistry, College of Natural and Computational Sciences Oda Bultum University, Chiro, \\ Ethiopia \\ ${ }^{2}$ Department of Chemistry, College of Natural and Computational Sciences, University of Gondar Gondar, \\ Ethiopia
}

*Corresponding Author: Meselu Eskezia, College of Natural and Computational Science, Department of Chemistry, Oda Bultum University, Chiro, Ethiopia

\begin{abstract}
The electrochemical property of paracetamol (PAR) was investigated in detail at a glassy carbon electrode and activated glassy carbon electrode. Cyclic voltammetry and differential pulse voltammetry were used as diagnostic techniques in the determination of paracetamol. The AGCE exhibited excellent electrocatalytic behaviour for the oxidation of PAR as evidenced by the enhancement of the oxidation peak current and the shift in the oxidation peak potential to less positive values by (13mv) in comparison with a bare GCE. In the present work the activated glassy carbon electrode was prepared by activating $200 s$ in a time base technique at a potential of $1750 \mathrm{mV}$. The electrode process of paracetamol was studied and some the experimental parameters which affect the response paracetamol, such as $\mathrm{pH}$, effect of PAR concentration and scan rate on AGC electrode. The analysis of cyclic voltammogram gave fundamental electrochemical parameters including the electroactive surface coverage ( $\Gamma$ ), the electron transfer coefficient $(\alpha)$ and the heterogeneous rate constant $\left(k_{s}\right)$. The equation of the calibration curve was found to be: $I_{p}(\mu A)=0.429 C(\mu$ $M)+6.43, R^{2}=0.993$. The LOD and LOQ for the developed method were determined to be $8 \times 10^{-8} \mathrm{~mol} \mathrm{~L}^{-1}$ and $2.6 \times 10^{-7} \mathrm{~mol} \mathrm{~L}^{-1}$ respectively.
\end{abstract}

Keywords: paracetamol, activated glassy carbon electrode, cyclic voltammetry, differential pulse voltammetry, Adsorption controlled and electron transfer coefficient

\section{INTRODUCTION}

Drug control has been on the global agenda for more a century in the world. So, drug analysis is an important tool for drug formulations which has great impact on public health. Hence, the development of simple, sensitive and rapid method to determine the active ingredients in drugs seems essential [1]. From the environmental point of view, pharmaceuticals including antibiotics are a new group of manmade chemicals of concern entering the environment at concentrations such that their health effects are unknown. So, paracetamol is one of the antibiotic drugs that used to fight infections caused by bacteria or other microbes [2].

Paracetamol, N-(4-hdroxyphenyl) acetamide is a widely used analgesic and antipyretic drug [3]. It is one of the most popular and widely used drugs for the treatment of pain and reduction of fever. It occupies a unique position among analgesic drugs [4]. Generally, paracetamol does not exhibit any harmful side effects, due to its rapidly and completely metabolized. However, the overdose of paracetamol can lead to the accumulation of toxics metabolites, which may cause liver disorder, kidney damage, skin rashes and inflammatory of the pancreas [5]. Paracetamol described as 4hydroxyacetanlide or N- acetyl-p-aminophenol is known as acetaminophen [7] and its chemical formula, $\mathrm{C}_{8} \mathrm{H}_{9} \mathrm{NO}_{2}$ and its structure is as shown below,<smiles>CC(=O)Nc1ccc(O)cc1</smiles>

Scheme1. Chemical structure of paracetamol 


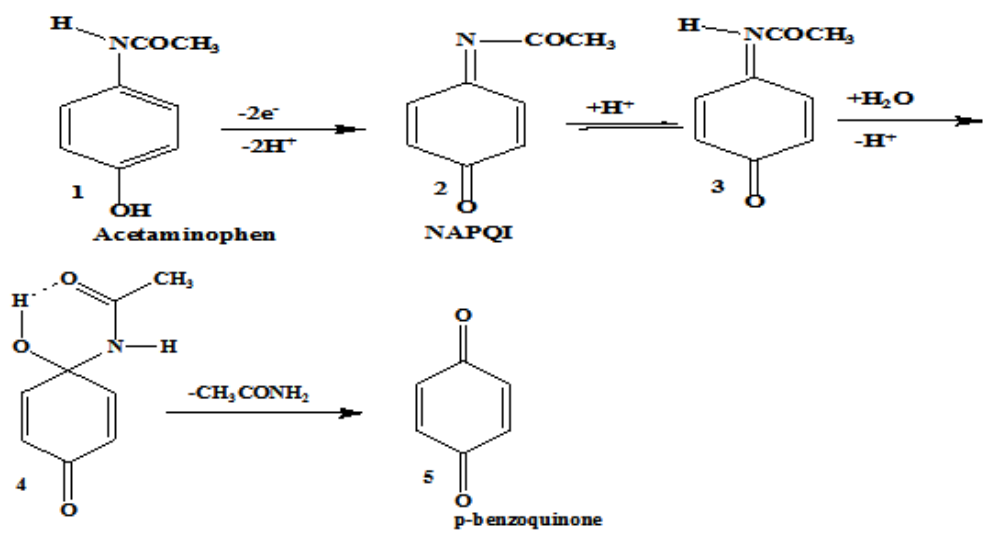

Scheme1. Mechanism of electrochemical oxidation of paracetamol

Nowadays, Paracetamol is widely used for its remarkable therapeutic characteristics thus precise determination and control of its quality is very important [8]. The development of simple, sensitive and accurate electroanalytical methods for the determination of paracetamol is very important. The various techniques have been employed for the determination of paracetamol in the body fluids and pharmaceuticals preparations including spectroscopy, chromatography, titrimetry and chemiluminscence $[8,11,12,14]$.

However, most of these techniques suffer from some disadvantages like; high cost, require extraction process, long analysis time, requirement for sample pre-treatment which is time consuming manipulation steps [18], need special training, portable [19], sophisticated instrument and making them unsuitable for routine analysis [15] and also these methods usually involves hydrolysis of paracetamol sample to 4-aminophenol, which the required the formation of a colored complex using an appropriate reagent, which takes a long time to perform [9].

On the other hand electrochemistry offers a number of very attractive advantages such as low cost, easy to manipulate, portable and fast. It has been widely employed in biological matrixes, pharmaceutical and some drugs containing tertiary amine functional group, due to its continuance, sensitivity, reproducibility and selectivity towards many target analytes [19]. Paracetamol is an electroactive compound (contains hydroxyl and NH groups on its aromatic rings) [10] and can be oxidized under suitable conditions, the use of electrochemical detection can be considered appropriate due to its rapid response and high sensitivity.

Many papers have been published about the electrochemical determination of paracetamol based on its oxidation behaviour with different electrodes such as, $\mathrm{C}_{60}$-modified glassy carbon electrode [12], Poly (4-vinyl pyridine) multi walled carbon nanotubes modified glassy carbon electrode [8], glassy carbon electrode [13], screen printed graphene electrode [19], gold nanoparticles electrodes [10], Bismuth oxide modified glassy carbon electrode [40] and Ni- modified electrode [39]. These reports showed good detection limits and sensitivity but, the main drawback is the need of extra time through the consuming modification process which usually involves several steps to incorporate the modifier to the substrate and also the costs [19].

In this paper, no study has been reported for determination of paracetamol using activated glassy carbon electrode. Activated glassy carbon-based electrodes usually have a wider potential range than the other solid electrodes because of their broad potential window, low background current; chemical inertness, low cost and suitability for various sensing and detection applications. However, electron transfer rates observed at carbon surfaces are often slower than those observed on noble metal electrodes [6].

\section{EXPERIMENTAL PART}

\subsection{Apparatus}

The electrochemical experiments were carried out in a three electrode systems containing $\mathrm{Ag} / \mathrm{AgCl}$ as a reference electrode, platinum wire as a counter electrode, bare glassy carbon electrode and activated glassy carbon electrode as a working electrode. The experiment and processing of data were made using CHI760E electrochemical workstation, CH Instrument (Inc., USA), which was connected to a Dell desktop computer with conventional three electrode configuration. The $\mathrm{pH}$ of the all solutions was 
measured with a JENWAY model 3510 digital $\mathrm{pH}$ meter with a combination glass electrode. Digital balance was used for mass measurements. The experiments were conducted in phosphate buffer solution at $\mathrm{pH}=7.0$ and at room temperature. Cyclic voltammetry and differential pulse voltammetry were used for this study.

\subsection{Chemicals and Reagents}

Pure paracetamol (Addis pharmaceuticals factory, Ethiopia), anhydrous di potassium hydrogen orthophosphate (BDH, England), potassium di hydrogen phosphate (Sigma-Aldrich, Switzerland), sodium hydroxide (BDH, England), India), sulphuric acid and paracetamol tablets (EPHARM) were used in the experiment without any purification. The stock solution of paracetamol was prepared and stored in a refrigerator until used. An aqueous solution was prepared daily of the working days by the dilution of the stock solution with phosphate buffer $\mathrm{pH}=7.0$. Phosphate buffer solutions $(0.1 \mathrm{M}$ $\mathrm{KH}_{2} \mathrm{PO}_{4}$ and $\mathrm{K}_{2} \mathrm{HPO}_{4}$ ) were prepared by using distilled water. Distilled water was used throughout the experiment. All chemicals were of analytical grade.

\subsection{Preparation of Activated Glassy Carbon Electrode}

Before activation, the surfaces of glassy carbon electrode ( $3 \mathrm{~mm}$ diameter) was polished to mirror with alumina slurry with a polishing pad and then thoroughly rinses with distilled water. The cleanness of the electrode was checked by a $0.5 \mathrm{M}$ sulfuric acid by running in cyclic voltammetry with a potential window between $-800 \mathrm{mV}-800 \mathrm{mV}$ at a scan rate of $100 \mathrm{mV} / \mathrm{s}$. Then the GC electrode was activated for $200 \mathrm{~s}$ in a time base technique at a potential of $1750 \mathrm{mV}$ in $0.1 \mathrm{M} \mathrm{KH}_{2} \mathrm{PO}_{4}$ and $\mathrm{K}_{2} \mathrm{HPO}_{4}$ phosphate buffer solution at $\mathrm{pH}=7.0$ and the $\mathrm{GC}$ electrode was activated by running cyclic voltammetry from 0.0 to $700 \mathrm{mV}$ for six cycles. The activated electrode was run in cyclic voltammetry until the voltammogram was stable.

\subsection{Preparation of Phosphate Buffer and Standard Solutions of the Analytes}

For all of the experiments, a mixture of $0.1 \mathrm{M} \mathrm{K}_{2} \mathrm{HPO}_{4}$ and $0.1 \mathrm{M}$ of $\mathrm{KH}_{2} \mathrm{PO}_{4}$ buffer solution $(\mathrm{pH}=7.0)$ was used. Concentrated $\mathrm{NaOH}$ and $\mathrm{HCl}$ solutions were used to adjust the $\mathrm{pH}$ of the buffer solutions. Stock solution of paracetamol $\left(1 \mathrm{mmol} \mathrm{L}^{-1}\right)$ prepared by dissolving $0.075 \mathrm{~g}$ of paracetamol in PBS of $\mathrm{pH}$ $=7.0$. The required amounts of paracetamol working solutions were prepared by diluting the stock solution with phosphate buffer solution supporting electrolyte $(\mathrm{pH}=7.0)$. Standard solutions in tablet were prepared by spiking of the drug in to an aqueous stock solution of standard paracetamol samples. The stock solution of uric acid was prepared by diluted with phosphate buffer solution.

\subsection{Sample Preparation from Tablets}

Ten tablets were purchased from commercially available pharmaceuticals drug shops $(500 \mathrm{mg}$ paracetamol per tablet). Five tablets were accurately weigh using digital balance and finely powder in mortar and pestle. Then an adequate amount of powder which was equivalent to the standard powder was weighed and added into 100 volumetric flasks and diluted with a $\mathrm{pH}=7.0$ phosphate buffer solution. Then the flask was thoroughly shaken until sample dissolved and the mixture was filled with the buffer solution.

\subsection{Electrochemical Measurements}

Electrochemical determination of paracetamol was carried out in a voltammetric cell $0.1 \mathrm{~mol} \mathrm{~L}^{-1} \mathrm{PBS}$ $(\mathrm{pH}=7.0)$ as a supporting electrolyte solution. The electrochemical behaviour of paracetamol at AGC electrode was investigated using cyclic voltammetry. The determination of paracetamol was carried out by using differential pulse voltammetry (DPV) by scanning the potential in the range from 0.0 to 500 $\mathrm{mV}$ at the pulse amplitude of $50 \mathrm{mV}$ and pulse repeat time of 0.5 seconds were used. The paracetamol concentrations were obtained by measuring the heights of the oxidative peak currents.

The detection limit was calculated as three times the standard deviation of phosphate buffer solution of paracetamol divided by the slope of the calibration curve and limit of quantification was calculated as ten times of the standard deviation phosphate buffer solution of paracetamol divided by the slope of the calibration curve.

\section{RESULTS AND DISCUSSION}

The electrochemical behaviour of PAR was examined using cyclic voltammetry at a scan rate of 100 $\mathrm{mV} / \mathrm{s}$. Figure 1 shows typical voltammogram of $0.1 \mathrm{mmol} \mathrm{L}^{-1}$ of PAR, in phosphate buffer solution $\mathrm{pH}$ 
$=7.0$ at a scan rate of $100 \mathrm{mV} / \mathrm{s}$ recorded at two different working electrodes (i,e. bare GC and AGCE. At bare GC electrode, Paracetamol shows quasi-reversible behaviour with relatively weak redox current peaks with high peak potential difference $\left(\Delta \mathrm{E}_{\mathrm{p}}=0.476 \mathrm{~V}\right.$ and slow electron transfer behaviour on bare GC electrode [9].

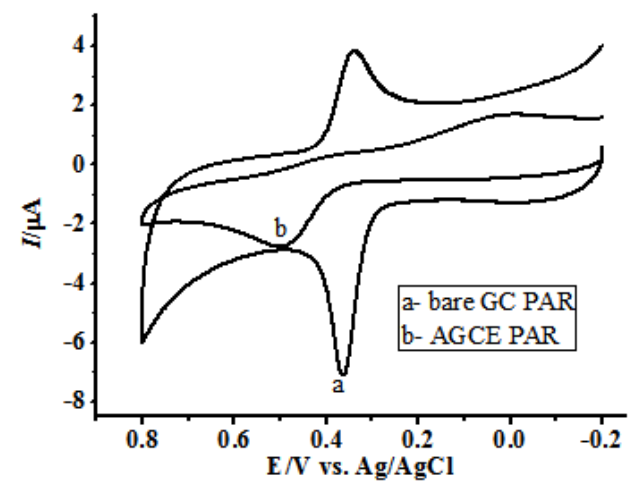

Figure1. Cyclic voltammogram of $0.1 \mathrm{mmol} \mathrm{L}^{-1}$ of PAR obtained at bare GCE (curve a) and AGCE (curve b) in $0.1 \mathrm{~mol} \mathrm{~L}^{-1} \mathrm{PBS}$ at $\mathrm{pH}=7.0$ with scan rate of $100 \mathrm{mV} / \mathrm{s}$ (Background subtracted)

Table1. Peak current and peak potential of PAR on bare and activated GC electrode taken from the above Figure 1.

\begin{tabular}{|c|c|c|c|c|c|c|c|c|c|c|}
\hline Analytes & \multicolumn{5}{|c|}{ Bare GC electrode } & \multicolumn{4}{|c|}{ Activated GC electrode } & \\
\hline \multirow{3}{*}{ PAR } & \multicolumn{2}{|c|}{$\begin{array}{l}\text { Peak current } \\
\quad(\mu \mathrm{A})\end{array}$} & \multicolumn{2}{|c|}{$\begin{array}{l}\text { Peak potential } \\
\text { (V) }\end{array}$} & $\begin{array}{l}\Delta \mathrm{E}_{\mathrm{p}} \\
(\mathrm{V})\end{array}$ & \multicolumn{2}{|c|}{$\begin{array}{l}\text { Peak current } \\
\quad(\mu \mathrm{A})\end{array}$} & \multicolumn{2}{|c|}{$\begin{array}{l}\text { Peak potential } \\
\text { (V) }\end{array}$} & $\begin{array}{l}\Delta \mathrm{E}_{\mathrm{p}} \\
(\mathrm{V})\end{array}$ \\
\hline & $\mathrm{I}_{\mathrm{pa}}$ & -2.71 & $\mathrm{E}_{\mathrm{pa}}$ & 0.479 & 0.450 & $\mathrm{I}_{\mathrm{pa}}$ & -7.07 & $\mathrm{E}_{\mathrm{pa}}$ & 0.36 & 0.02 \\
\hline & $\mathrm{I}_{\mathrm{pc}}$ & 1.607 & $\mathrm{E}_{\mathrm{pc}}$ & 0.29 & & $\overline{I_{p c}}$ & 3.78 & $\mathrm{E}_{\mathrm{pc}}$ & 0.34 & \\
\hline
\end{tabular}

In comparison to unactivated (bare) GC electrode, electrochemical response of paracetamol at activated glassy carbon electrode after activated the electrode shows both cathodic and anodic peak current are significantly increased with reducing the over potential by $0.130 \mathrm{~V}$. This indicates activation of electrode alters the oxidation of paracetamol from quasi reversible to reversible reaction.

The peak-to-peak separation of activated glassy carbon electrode $\left(\Delta \mathrm{E}_{\mathrm{p}}=0.025 \mathrm{~V}\right)$ is much smaller than that of the bare GC electrode [10]. The ratio of redox peak current $\left(\mathrm{I}_{\mathrm{pa}} \mathrm{I}_{\mathrm{pc}}\right)$ was 1.85 , which shows the characteristics of irreversible electrode process. However for reversible electrode reaction the ratio of $\mathrm{I}_{\mathrm{pa}}$ to that of $\mathrm{I}_{\mathrm{pc}}$ is one [7].

Activated GC electrode shows a fast electron transfer rate (kinetics) due to good conductivity and a large capacitive current of the electrode. This indicates that the activated glass carbon electrode shows electro-catalytic activity towards paracetamol. To generalized the above discussion the catalytic properties of activated glassy carbon electrode surface caused decrease the over potential of oxidation reaction, increase the sharpness of both cathodic and anodic peak current and the reversibility of electron transfer process [19].

\subsection{Effect of Operational Parameters}

\subsubsection{Effect of solution $\mathrm{pH}$}

In order to optimize the response of activated GC electrode for paracetamol oxidation, the effect of $\mathrm{pH}$ on the electrochemical oxidation was investigated by cyclic voltammetry technique at different $\mathrm{pH}$ using phosphate buffer solution with a $\mathrm{pH}$ range of $4-10$ at a scan rate of $100 \mathrm{mV} / \mathrm{s}$ to determine its effect on the catalytic oxidation of $0.1 \mathrm{mmol} \mathrm{L}^{-1}$ paracetamol at activated GC electrode. As shown Figure 2 , the $\mathrm{pH}$ of the solution obviously influenced the potential and the currents of both cathodic and anodic peaks of paracetamol. From the figure 3 it can be seen that the peak currents increase with increasing $\mathrm{pH}$ up to 7.0 and the peak currents slowly decreased from 7-10 (i,e higher $\mathrm{pH}$ values), suggested that 
the oxidation of paracetamol is kinetically less favourable at higher $\mathrm{pH}$ values. In addition, Figure 8 also shows the relationship between the peak potential of paracetamol and the $\mathrm{pH}$ value. As can be seen that, both oxidation potential $\left(\mathrm{E}_{\mathrm{pa}}\right)$ and reduction potential $\left(\mathrm{E}_{\mathrm{pc}}\right)$ shift to negatively direction with the increase of $\mathrm{pH}$ from 7.0 to 10 . This observation is strong evidence that reflects the involvement of protons in the electrode process [39]. Furthermore, the potential was shifted to the direction of more negative potentials with increasing $\mathrm{pH}$ values, i.e. to the lower potential, suggesting that the ease of oxidation the protonated molecules [40]. The better sensitivity and shapes of voltammogram (maximum peak current) was observed at $\mathrm{pH}=7.0$ suggested it as optimal $\mathrm{pH}$ value.

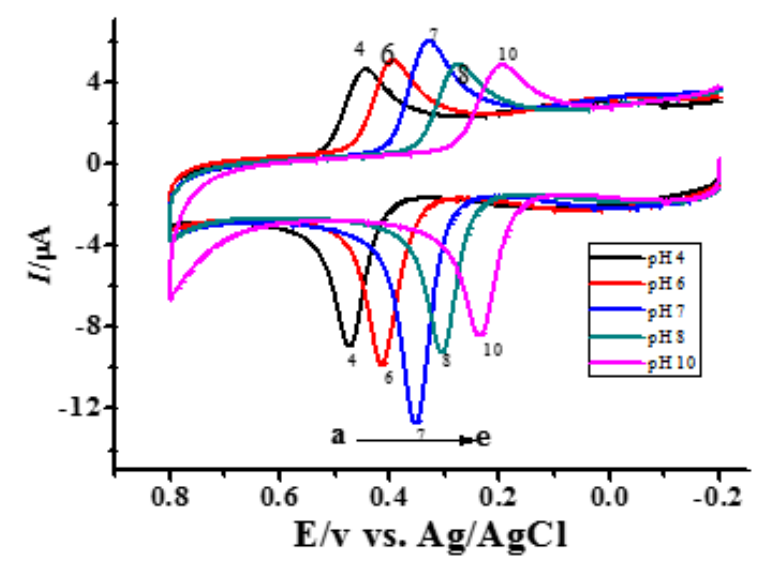

Figure2. Cyclic voltammogram of $0.1 \mathrm{mmol} L^{-1}$ of PAR in $0.1 \mathrm{~mol} \mathrm{~L}^{-1} P B S$ at different $\mathrm{pH}$ values $(4,6,7,8$ and 10) with a scan rate of $100 \mathrm{mV} / \mathrm{s}$ using AGCE (Background subtracted).

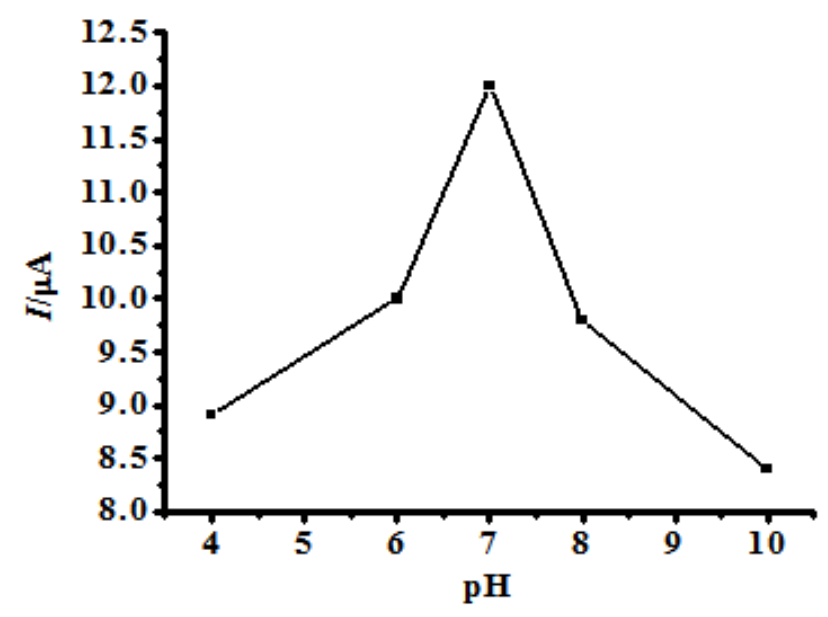

Figure3. The relation between peak current $\left(I_{p a}\right)$ and $p H$ at a scan rate of $100 \mathrm{mV} / \mathrm{s}$.

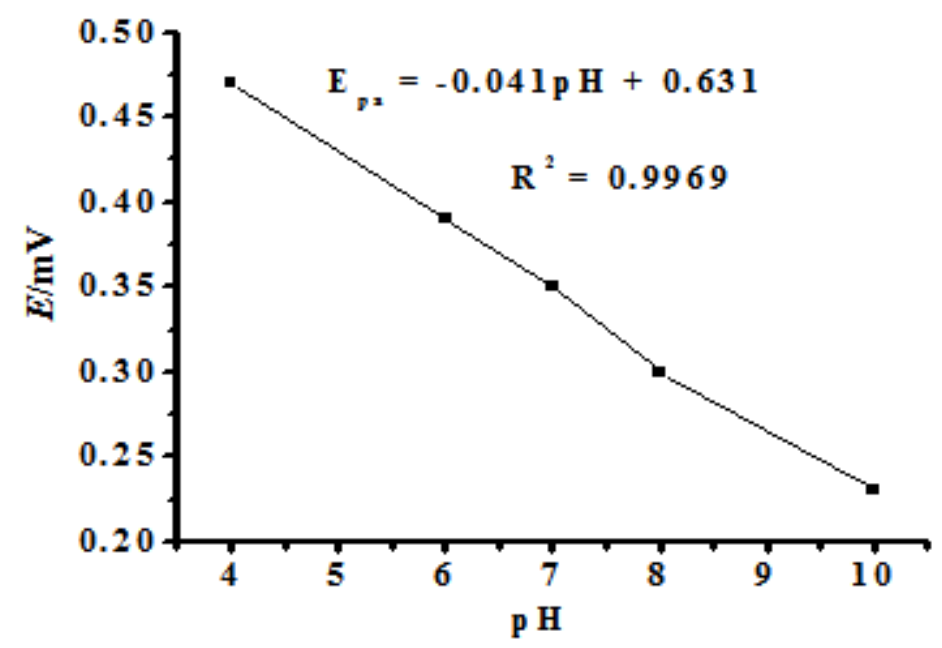

Figure4. The relation between peak potential $\left(E_{p a}\right)$ and $p H$ at a scan rate of $100 \mathrm{mV} / \mathrm{s}$. 


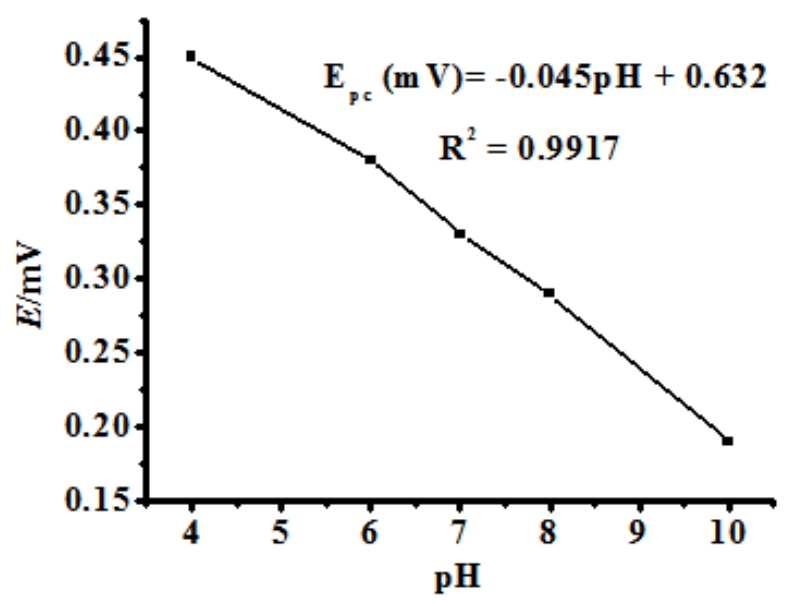

Figure5. The relation between cathodic peak potential $\left(E_{p c}\right)$ and $p H$ at a scan rate of $100 \mathrm{mV} / \mathrm{s}$ using AGCE.

Generally, the electrochemical oxidation of paracetamol at activated glassy carbon electrode is $\mathrm{pH}$ dependent. At a pH near to 7.0 N-acetyl-p-Quinoneimine exists in its stable and unprotonated form [7]. If the $\mathrm{pH}$ was higher than 7, the drugs inclined to decompose, resulting in the decrease of the response. As can be seen, the peak potential for paracetamol oxidation varies linearly with. Therefore, $\mathrm{pH}=7.0$ was better for further analysis.

The linear dependence of the peak potential on $\mathrm{pH}$ was represented by the equation: $\mathrm{E}_{\mathrm{pa}}(\mathrm{V})=-0.041 \mathrm{pH}$ $+0.631\left(\mathrm{R}^{2}=0.9969\right)$ and $\mathrm{E}_{\mathrm{pc}}(\mathrm{mV})=-0.045 \mathrm{pH}+0.632\left(\mathrm{R}^{2}=0.9917\right)$. The slopes of $-0.045 \mathrm{~V} / \mathrm{pH}$ and $-0.041 \mathrm{~V} / \mathrm{pH}$ and according to the equation of $\mathrm{dE}_{\mathrm{pa}} / \mathrm{dpH}=2.303 \mathrm{mRT} / \mathrm{nF}$ [17], the ratio of the number of protons $(\mathrm{m})$ and the number of electrons $(\mathrm{n})$ in the oxidation process was calculated to be 0.7 , which is close to 1. This indicates that equal number of electrons and protons were involved in the electrochemical oxidation of paracetamol at activated GC electrode within the studied $\mathrm{pH}$ range (scheme 4), which is in agreement with the reported literature $[8,9,10]$.

The number of electron involved in electrochemical reaction of PAR was found to be calculated from the change in potential $\left(\Delta E_{p}\right)$ of AGCE. In this investigation the change in potential of PAR on AGCE was fond to be $30 \mathrm{mV}$. If the change in potential was found to be $30 \mathrm{mV}$, the number of electron involved is two and the reaction is reversible [37].

\subsubsection{Effect of Scan Rate on Peak Current and Peak Potential}

The influence of varying scan rates on the electrochemical response of paracetamol at activated GC electrode was investigated by cyclic voltammetry. The effect of scan rate on the oxidation peak current of $0.1 \mathrm{mmol} \mathrm{L}^{-1}$ paracetamol using AGC electrode as working electrode in $0.1 \mathrm{~mol} \mathrm{~L}^{-1} \mathrm{PBS}(\mathrm{pH}=7.0)$ was studied by varying the scan rate from $20-300 \mathrm{mV} / \mathrm{s}$. The resulting voltammogram as shown below in Figure 6,

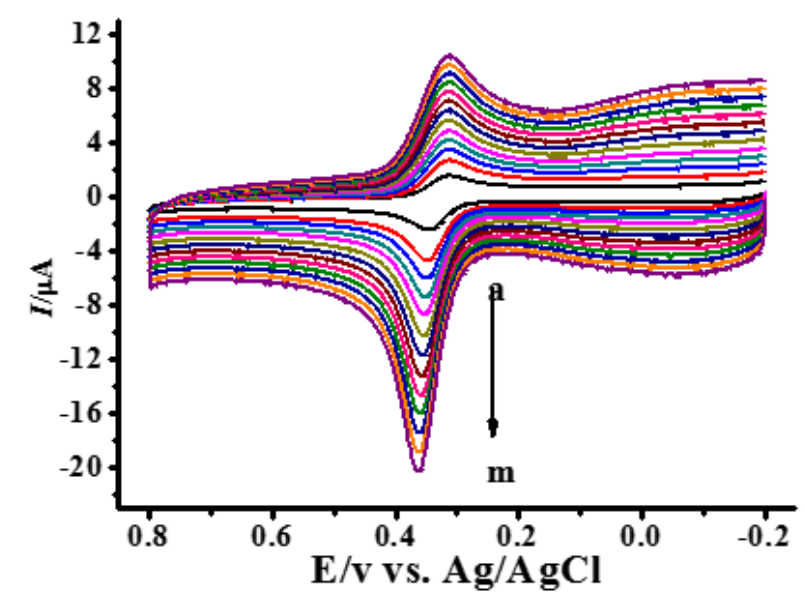

Figure6. Cyclic voltammogram of $0.1 \mathrm{mmol} \mathrm{L}^{-1}$ PAR at different scan rates in the range (20, 40, 60, 80, 100, 125, 150, 175, 200, 225, 250, 275 and $300 \mathrm{mV} / \mathrm{s})$ in 0.1 mol L $\mathrm{L}^{-1} \mathrm{PBS}(\mathrm{pH}=7.0)$ at AGCE (Background subtracted). 
From figure 6 voltammogram observed that, the oxidation peak current of paracetamol increased linearly as the scan rate increased gradually and the oxidation potential shifted towards more positive potential (i.e. increase over potential) and due to excellent peak response. This indicated that the oxidation of paracetamol is reversible at activated glassy carbon electrode. The relation between peak current versus scan rate and square root of scan rate were drawn in Figure 7 and 8 respectively.

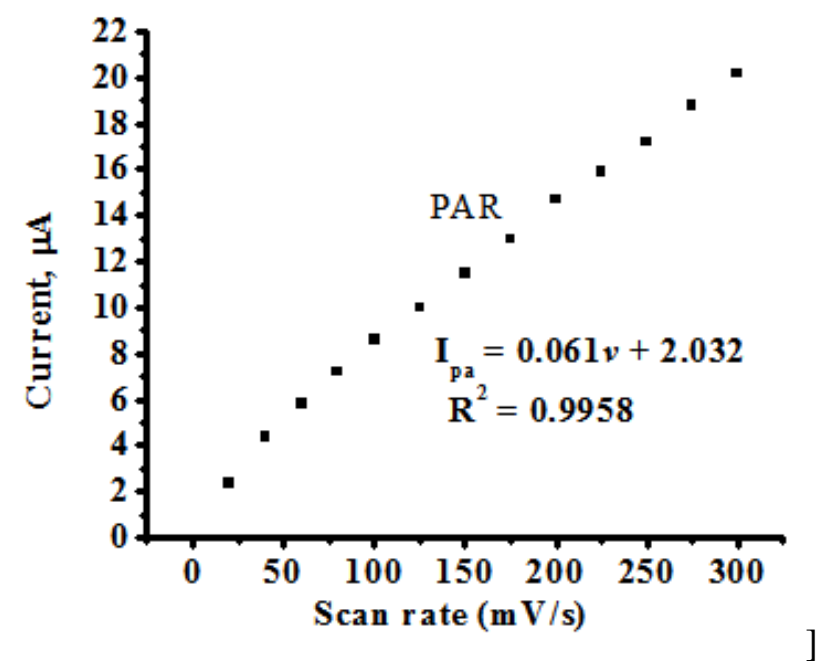

Figure7. Effect of variation of scan rate on the anodic peak current of $0.1 \mathrm{mmol} \mathrm{L} \mathrm{L}^{-1}$ of PAR in $0.1 \mathrm{~mol} \mathrm{~L}-1$ of PBS at $\mathrm{pH}=7.0$.

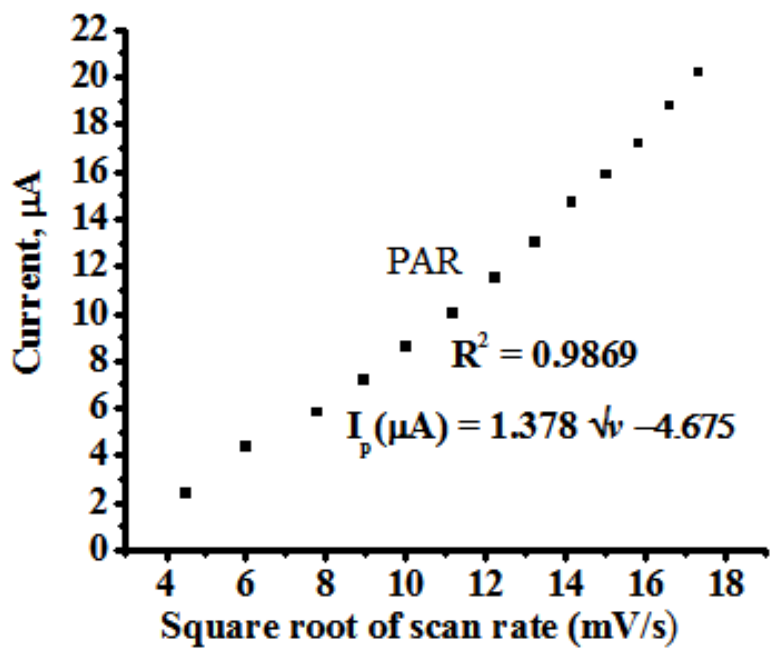

Figure8. The dependence of peak current of $0.1 \mathrm{mmolL}^{-1}$ of PAR on the square root of scan rate at AGCE in $0.1 \mathrm{~mol} L^{-1} \mathrm{PBS}$ at $\mathrm{pH}=7.0$.

The linear equation of oxidation peak current on both scan rate and square root of scan rate as follows, $\mathrm{I}_{\mathrm{pa}}=0.061 v+2.032\left(\mathrm{R}^{2}=0.998\right)$; and the oxidation peak current increased linearly as the square root of the scan rate, $\sqrt{v}, \mathrm{I}_{\mathrm{pa}}=1.37 \sqrt{v}-4.675\left(\mathrm{R}^{2}=0.9869\right)$. The dependence of anodic peak current on the scan rate indicated that the electrode transfer reaction of paracetamol was adsorption controlled. Further evidence for non-diffusion behaviour of paracetamol was obtained, when the working electrode was switched to a medium containing only phosphate buffer solution after being in voltammetric measurements of paracetamol solution, voltammetric signal was observed [7].This indicates paracetamol shows adsorption controlled process. From these results, a scan rate of $100 \mathrm{mV} \mathrm{s}{ }^{-1}$ was chosen for further analysis.

\subsection{Differential Pulse Voltammetric Investigation of PAR Using AGCE}

To further increase the sensitivity and lower detection limit, a more sensitive technique compared to cyclic voltammetry is differential pulse technique used to detect PAR at AGC electrode to evaluate calibration characteristics, validation (such as linearity, accuracy of real sample, limit of detection and limit of quantification). 


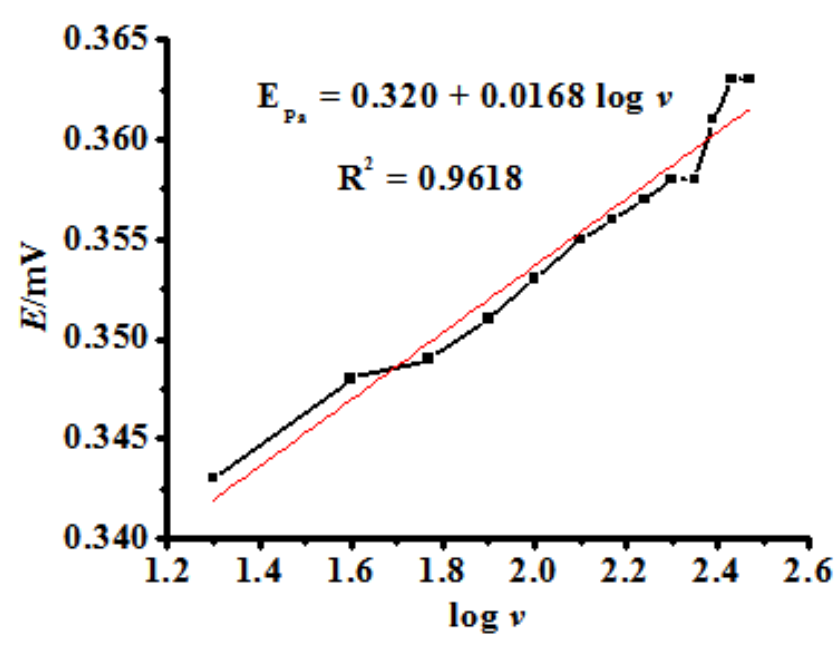

Figure9. Graph of $E_{p a} v s . \log v$.

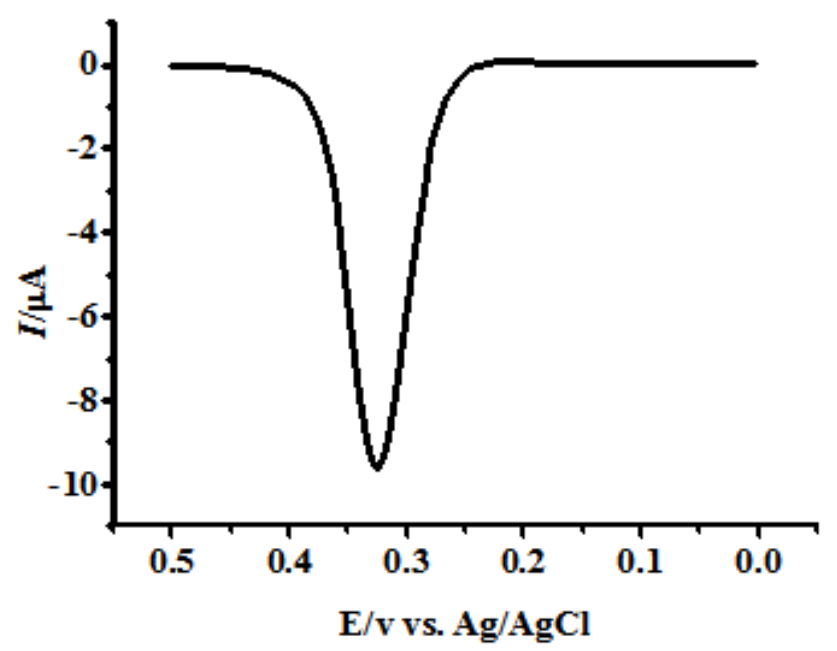

Figure10. Differential pulse voltammogram of $0.1 \mathrm{mmol} L^{-1} P A R$ in $0.1 \mathrm{~mol}^{-1} P B S(p H=7.0)$ at AGCE with a scan rate of $100 \mathrm{mV} / \mathrm{s}$ (Background subtracted).

Table2. Determination of paracetamol in formulation EPHARM tablets with AGCE.

\begin{tabular}{|l|l|l|l|}
\hline Analyte & $\begin{array}{l}\text { Concentration } \\
\text { expected } \\
(\mu \mathrm{mol} \mathrm{L}\end{array}$ & $\begin{array}{l}\text { Concentration found } \\
\left(\mu \mathrm{mol} \mathrm{L}^{-1}\right)\end{array}$ & $\%$ Recovery \\
\hline \multirow{2}{*}{ EPHARM } & 40 & 40.6 & 105 \\
\cline { 2 - 5 } & 50 & 51.1 & \\
\hline
\end{tabular}

Figure 10. shows the differential pulse voltammogram of $1.0 \times 10^{-2} \mathrm{M}$ paracetamol. Only one sharp peak was observed at $325 \mathrm{mV}$, which indicates that paracetamol undergoes only one step electrochemical reaction at glassy carbon electrode when the potential was run in the positive direction, i.e., oxidation reaction at $325 \mathrm{mV}$.

As can be seen, the above voltammogram shows the peak current response in CV and differential pulse voltammogram was -7.10 and $-9.66 \mu \mathrm{A}$ respectively. This shows the peak current enhancement of paracetamol response was better in differential pulse voltammetric than cyclic voltammetry. So, differential pulse voltammetric was better peak current enhancement and good sensitive for the determination of paracetamol at AGCE.

\subsection{Effect of Concentration and Detection Limit}

The effects of varying paracetamol concentration on the differential pulse voltammetric peak current response of paracetamol was studied at activated glassy carbon electrode. The Figure 11 below shows DP voltammogram of PAR from $1 \mu \mathrm{mol} \mathrm{L}^{-1}-60 \mu \mathrm{mol} \mathrm{L}^{-1}$. 


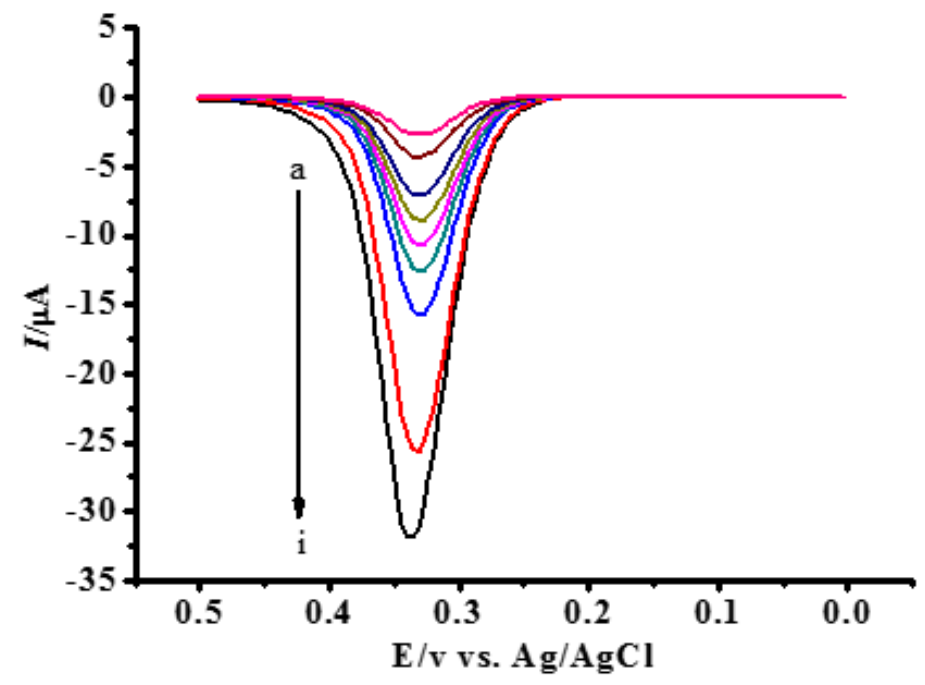

Figure11. Differential pulse voltammogram of PAR at different concentrations range (1, 2, 4, 6, 8, 10, 20, 40 and $\left.60 \mu \mathrm{mol} \mathrm{L} \mathrm{L}^{-1}\right)$ in $0.1 \mathrm{~mol} \mathrm{~L}^{-1} \mathrm{PBS} \mathrm{pH}=7.0$ at the scan rate of $100 \mathrm{mV} / \mathrm{s}$ (Background subtracted).

The figure 11 shows the oxidative peak current of paracetamol increases rapidly and linearly with increasing concentration from $\left(1-60 \mu \mathrm{mol} \mathrm{L}^{-1}\right)$. The resulting differential voltammogram consists of current peaks and the height of these current peaks is directly proportional to the paracetamol concentration [1].The enhancement of peak current on increasing paracetamol concentration in the above voltammogram is due to the presence of more ions in the solution which makes the flow of electrons easy [7]. The plot of differential pulse voltammetric peak current versus concentrations of paracetamol was found to be in the linear range of $8-60 \mu \mathrm{mol} \mathrm{L}^{-1}$ with correlation coefficient $\mathrm{r}^{2}=$ 0.996 with the equation $\mathrm{I}_{\mathrm{pa}}(\mu \mathrm{A})=6.43+0.429 \mathrm{C}\left(\mu \mathrm{mol} \mathrm{L}^{-1}\right)$.

The detection limit of PAR can be calculated by measuring the differential pulse voltammetry of activated GC electrode without PAR 8 times and calculate the standard deviations of 8 repeat measurements. The standard deviation of 8 measurements was 0.0115 . The magnitude of detection limit calculated by using the formula; LOD $=3 \delta / \mathrm{m}$, where $\delta$ represent the standard deviation of blank solution of 8 measurements and $\mathrm{m}$ represents the slope of the calibration curve. The detection limit was found to be $8 \times 10^{-8} \mathrm{~mol} \mathrm{~L}^{-1}$

The limit of quantification was calculated by the equation: $\mathrm{LOQ}=10 \delta / \mathrm{m}$. The limit of quantification was found to be $2.6 \times 10^{-7} \mathrm{~mol} \mathrm{~L}^{-1}$. The relative standard deviation (RSD) was calculated by standard deviation divided by the mean of 8 repeated measurement times 100 . The relative standard deviation was calculated to be $1.02 \%$.

As can be seen from fig 12, the peak currents of paracetamol concentration from 1 to $6 \mu$ mol $\mathrm{L}^{-1}$ was lie outside the straight line. Therefore, the linear range extends only from 8 to $60 \mu \mathrm{mol} \mathrm{L}^{-1}$ paracetamol concentration.

\subsection{Determination of Degree of Recovery of Paracetamol}

To determine whether excipients in the tablets interfered or not, the accuracy of the proposed method was evaluated by recovery tests without spiking these samples and also on spiking known standard concentration of paracetamol in these tablets sample. The recovery results of paracetamol obtained by using DPV technique with AGC electrode, for all spiked and non spiked tablet sample have been calculated by using the concentration of spiked sample obtained from the calibration curve minus the concentration of non spiked sample divided by the concentration of the analytes added to the spiked portion $\left(10 \mu \mathrm{molL}^{-1}\right)$ times 100 .

$\%$ Recovery $=\frac{S-U}{A} \times 100$

Where S represents the spiked sample paracetamol in $\mu \mathrm{mol} \mathrm{L}^{-1}, \mathrm{U}$ represents un-spiked sample in $\mu$ mol L $\mathrm{L}^{-1}$ and $\mathrm{A}$ represents the concentration of analyte added to the spiked portion $\left(10 \mu \mathrm{mol} \mathrm{L}^{-1}\right)$. 
The \%recovery of PAR in EPHARM tablets was calculated to be $105 \%$, indicating that the AGCE could be successfully applied for PAR determination in tablets with a good recovery. The analysis of the obtained responses allowed concluding that the drug excipients do not significantly interfere with the proposed method. The amount of PAR on pharmaceuticals formulations of EPHARM was good agreement with the tablet manufacturer.

\subsection{Interference Study on the Behaviour of Paracetamol}

Paracetamol generally suffers from the interferences such as p-aminophenol, caffeine, ascorbic acid, uric acid and glucose. Hence, in this study a systematic study of interference due to the presence of uric acid only [12]. The interference UA was examined on AGCE on the determination of paracetamol. The oxidation potential of PAR is the same as that of UA, $0.3 \mathrm{~V}$ and that of UA is very close at, $0.2 \mathrm{~V}$. The voltammetric current response of successive addition PAR were recorded in Figure 12, using AGC electrode in PBS $(\mathrm{pH}=7.0)$, containing equal amount of $0.1 \mathrm{mmol} \mathrm{L}^{-1} \mathrm{PAR}$ and $0.1 \mathrm{mmol} \mathrm{L}^{-1} \mathrm{UA}$ to check the selectivity of the method in the presence of interference.

As shown the figure 12, two completely resolved peaks are observed at AGCE and the $\mathrm{E}_{\mathrm{p}}$ of uric acid was observed at positive potential $(\sim 25 \mathrm{mV})$ with AGCE also the potential peak to separation of the two analytes were $90 \mathrm{mV}$. The well-defined peak of PAR was obtained at AGCE with good peak separation from UA [12]. Generally, the above voltammogram was observed that UA affect peak current for PAR compared with PAR without UA under the potential range used (i.e decrease the peak current and causes to the broadness of the peak of paracetamol), but do not affect the peak potential of paracetamol.

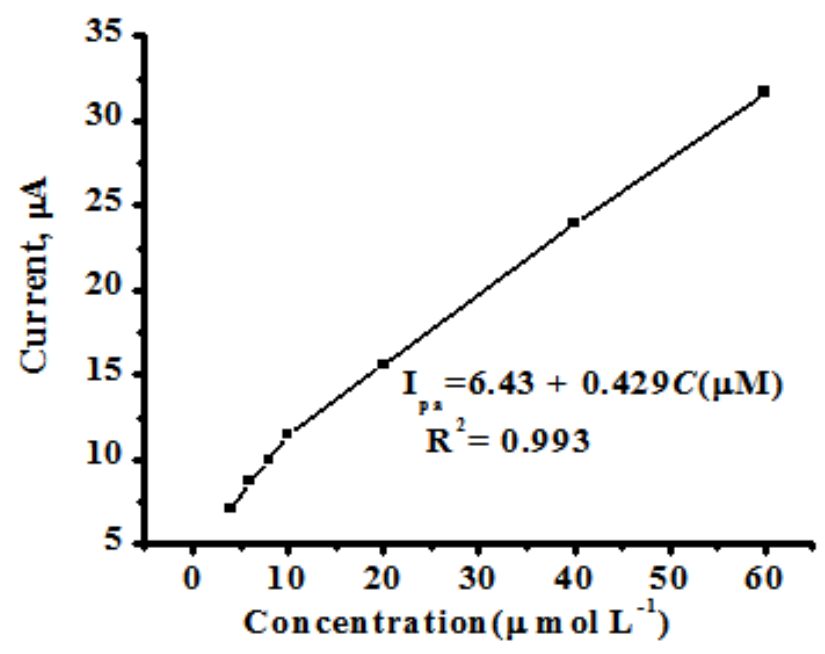

Figure12. Plot of peak current versus concentration.

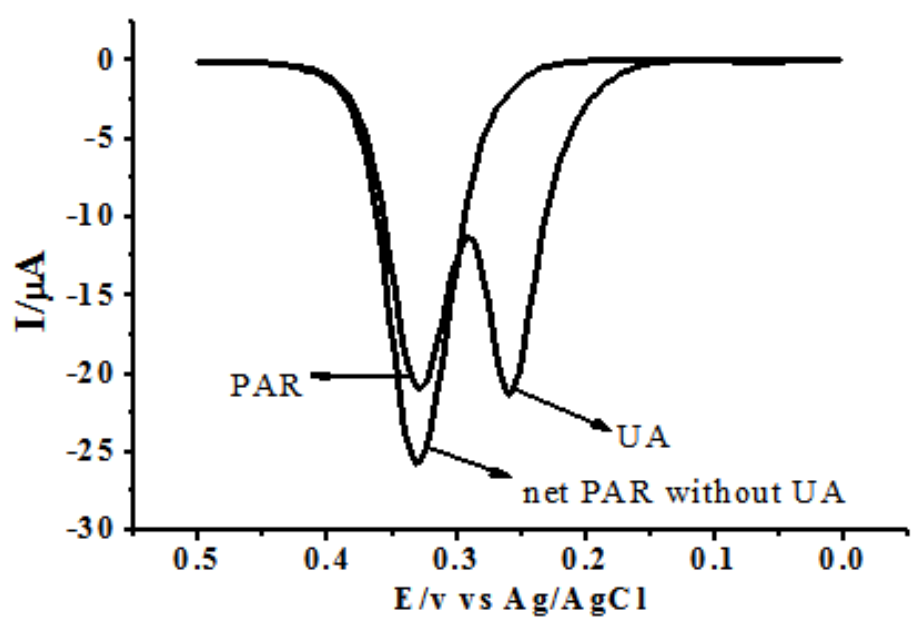

Figure12. Differential pulse voltammogram of $0.1 \mathrm{~mol} \mathrm{~L}^{-1}$ of $P B S(p H=7.0)$ containing $0.1 \mathrm{mmol} L^{-1} P A R$ and $0.1 \mathrm{mmol} \mathrm{L} \mathrm{L}^{-1} \mathrm{UA}$ using AGCE at a scan rate of $100 \mathrm{mV} / \mathrm{s}$ (Background subtracted).

The percent changes in the peak current response of UA was $2.02 \%$, suggested that UA do not significantly interfere in the determination of paracetamol. 


\subsection{Comparison of the Proposed Method with Other Methods}

The electrochemical determination of paracetamol in this study is compared to other methods as summarised in table 3. As can be seen that the electrochemical determination of PAR in different electrode such as, nano-gold modified carbon paste electrode [21], $\mathrm{C}_{60}$-modified GCE [12], Poly (4vinylpyridine/multi-walled carbon nanotubes modified GCE [8], GCE [13] and Poly (3, 4ethylenedioxythiophene modified GCE [9]. This electrode were provides a reasonable analytical performance and good detection limit. But the activated glassy carbon electrode offers easy to activate with a potential and rapid electrode preparation compared to other electrodes.

Table3. Comparison between the results of the present study and the studies recently reported in literature.

\begin{tabular}{|c|c|c|c|c|}
\hline Electrodes & Techniques & $\begin{array}{c}\text { Linear dynamic } \\
\text { Range }\end{array}$ & Detection limit & References \\
\hline NiHCFMCPE & CV & $5 \times 10^{-4}-7.5 \times 10^{-3} \mathrm{M}$ & $8.89 \times 10^{-5} \mathrm{M}$ & {$[7]$} \\
\hline PEDOT/GCE & DPV & $1.5-150 \mu \mathrm{M}$ & $1.3 \mu \mathrm{M}$ & {$[9]$} \\
\hline PolyAniBMCPE & DPV & $0.1-0.8 \mu \mathrm{M}$ & $1.179 \mu \mathrm{M}$ & {$[12]$} \\
\hline C60-modified GCE & DPV & $0.05-1.5 \mathrm{mM}$ & $0.05 \mathrm{mM}$ & {$[13]$} \\
\hline GCE & DPV & $4 \times 10^{-6}-1 \times 10^{-4} \mathrm{M}$ & $3.69 \times 10^{-7} \mathrm{M}$ & {$[17]$} \\
\hline GNMCPE & DPV & $5 \times 10^{-8}-2.7 \times 10^{-4} \mathrm{M}$ & $1.46 \times 10^{-8} \mathrm{M}$ & {$[19]$} \\
\hline SPGrE & CV & $0.1-50 \mu \mathrm{M}$ & $20 \mathrm{nM}$ & The present \\
\hline AGCE & DPV & $8-60 \mu \mathrm{M}$ & $8 \times 10^{-8} \mathrm{M}$ & \\
\hline
\end{tabular}

\section{CONCLUSiON}

In the present study, an easily activated glassy carbon electrode was used to investigate the detailed electrochemical behaviour of paracetamol. The reported activated electrode significantly improved the electrochemical response of PAR and clearly demonstrates the excellent electro-catalytic properties of the AGCE toward the oxidation of paracetamol. Compared to other modified electrode, the potential activated glass carbon electrode was easily activated by applied potential and no need steps to activate. But the chemically modified GCE is the need of extra time through the consuming modification process which usually involves several steps to incorporate modifier to the substrate and also the costs.

The proposed method is clean, easy to set up (no need of special training) and furthermore, it does not require any expensive reagents apart from a simple buffer solution, and more time efficient. The activated glassy carbon electrode showed a linear response range between $8-60 \mu \mathrm{mol} \mathrm{L}^{-1}$, with a detection limit of $8.0 \times 10^{-8} \mathrm{~mol} \mathrm{~L}^{-1}$. The proposed method was applied for paracetamol determination in EPHARM commercial tablets with a recovery of $105 \%$.

\section{ACKNOWLEDGEMENT}

The authors are grateful to Department of Chemistry, College of Natural and Computational Sciences, Gondar University and Bahir Dar University give the facilities to do this research work.

\section{REFERENCES}

[1] Patil, D. G., Gokavi, N. M., Bagoji, A. M., \& Nandibewoor,T. S. (2016). Electrochemical Characterization and determination of paracetamol and tramadol drug using graphite pencil electrode. Analytical and Bioanalytical Electrochemistry. 8, 78-91.

[2] Alemayehu, T., \& Sergawie, A. (2014). Electrochemical behaviour of chloramphenicol and its determination by using cyclic voltammetry. International Journal of Inovation and Scientific Research. 8, 159-171.

[3] Bidkorbeh, G. F., Shahrokhiana, S., Mohammadi, A.,\& Dinarvand, R. (2010). Simultaneous voltammetric determination of tramadol and acetaminophen using carbon nanoparticles modified glassy carbon electrode. Electrochimica Acta. 55, 2752-2759. 
[4] Belal, T., Awad, T., \& Clarck, R. C. (2009). Determination of paracetamol and tramadol hydrochloride in pharmaceuticals mixture using HPLC-GC-MS. Journal of Chromatographic Science. 47, 111-113.

[5] Yin, H., Shang, K., \& Meng, X. (2011). Voltammetric sensing of paracetamol, dopamin and 4-aminophenol at a glassy carbon electrode coated with gold nanoparticles and an organophillic layered double hydroxide. Microchim Acta. 175, 39-46.

[6] Sanghavi, J. B., \& Srivastava, K. A. (2011). Simultaneous voltammetric determination of tramadol and acetaminophen using Dowex 50wx2 and gold nanoparticles modified glass carbon paste electrode. Analytical Chimica Acta. 706, 246-254.

[7] Gete, G. T., \& Kassaw, M. M. (2016). Determination of paracetamol and kinetics Parameters using Nickel hexacynoferrate modified carbon paste electrode. International Journal of Advanced Research. 4, 10871093.

[8] Ghani, H., Tehrani, A. M. R., Ali, M. S. A., Mohamed, N., \& Ghani, A. S. (2013). Sensitive voltammetric determination of paracetamol by poly (4- vinylpyridine) /multi- walled carbon nanotubes modified glassy carbon electrode. Analytical Chimica Acta. 765, 70-76.

[9] Solomon, M., Shimelis, A., Merid, T., \& Theodros, S. (2011). Voltammetric Determination of Paracetamol with Poly (3, 4 Ethylenedioxythiophene) ModifiedGlassy Carbon Electrode. Analytical and Bioanalytical Electrochemistry. 3, 38-50.

[10] Vishwanath, C.C., \& Bahaddurghatta, E. K. S. (2014). Electrochemical Studies of Paracetamol at Poly (Aniline Blue) Modified Carbon Paste Electrode: A Voltammetric Study. Journal of Analytical and Bioanalytical Electrochemistry. 6, 573-582.

[11] Suresh, E., Sundaram, K., Kavitha, B., Rayappan, M. S., \& Kumar, S.N. (2016). Simultaneous Electrochemical Determination of Paracetamol and Ibuprofen at the Glassy Carbon Electrode. Journal of Advanced Chemical Sciences. 4, 369-372.

[12] Goyal, N.R., \& Singh, P. S. (2006). Voltammetric determination of paracetamol at C60- Modified glassy carbon electrode. Electrochimica Acta. 51, 3008-3012.

[13] Engin, C., Yilmaz, S., Saglikoglu, G., Yagmur, S., \& Sadikoglu, M. (2015). Electroanalytical Investigation of Paracetamol on Glassy Carbon Electrode by Voltammetry. International Journal of Electrochemical Sciences. 10, 1916- 1925.

[14] Dai, Y., Li, X., Lu, X., \& Kan, X. (2016). Voltammetric determination of paracetamol using a Glassy carbon electrode modified with Prussian Blue and a molecularly imprinted polymer. Microchim Acta. 183, 27712778.

[15] Babaei, A., Taheri, R. A., \& Afrasiabi, M. (2011). A multi-walled carbon nanotube-modified glassy carbon electrode as a new sensor for the sensitive determination of Paracetamol and Tramadol in pharmaceuticals preparations and biological fluids. Journal of Brazil Chemical Society. 22, 1549-1558.

[16] Khoshsafar, H., Afkhami, A., Bagheri, H., \& Madrakian, T. (2014). Preparation of NiF2O4/Graphene nanocomposite and its application as a modifier for the fabrication of an electrochemical sensor for the simultaneous determination of tramadol and Acetaminophen. Analytical Chimica Acta. 831, 50-59.

[17] Kang, X., Wang, J., Wu, H., Liu, J., Aksay, A.I., \&Lin, Y. (2010). A graphene- based Electrochemical sensor for sensitive detection of paracetamol. Journal of Talanta. 81, 754- 759.

[18] Sadok, L., \& Rotko. T. K. (2015). New, simple and sensitive voltammetric procedure for determination of paracetamol in pharmaceuticals formulations. Journal of Analytical Electrochemistry. 1, 2470-2482.

[19] Fernandez, C., Heger, Z., Kizek, R., Ramakrishnappa, T., Borun, A., \& Faisal, H. N. (2015).

[20] The electrochemical oxidation of paracetamol and its voltammetric sensing in Biological samples based on screen printed graphene electrodes. International Journal of Electrochemical Science. 10, 7440-7452.

[21] Gete, G. T., \& Kassaw, M. M. (2016). Cyclic voltammetric studies of paracetamol at Nickel cyanoferrate modified carbon paste electrode. Journal of Natural Sciences Research. 6, 2224 - 2253.

[22] Atta, N.F., Galal, A., \& Azab, S. M. (2011). Electrochemical determination of paracetamol using gold nanoparticles. International Journal of Electrochemical Society. 6, 5082- 5092.

[23] Zidan, M., Tee, W. T., Abdullah, H. A., Zainal, Z., \& Kheng, J. G. (2010). Electrochemical oxidation of paracetamol mediated by Zinc oxide modified glassy Carbon electrode. Journal of Basic and Applied Sciences. 4, 6025-6030.

[24] Naraya, S., Kumari, P., Sindhu, K. R., Tiwari, A., \& Ghosh, M. (2009). Simultaneous Analysis of paracetamol and tramadol- analytical method development and validation. Der Pharma Chemical. 1, 72-78.

[25] Dekanski, A., Stevanovic, J., Stevanovic, R., Nikolic, Z. B., \& Jovanovic, M. V. (2001). Characterization and electrochemical activation of glassy carbon electrodes. Carbon. 39, 1195- 1205.

[26] Weisshaar, H. D., \& Kuwana, T. (1985). Considerations for polishing glassy carbon to a scratch-free finish. Analytical Chemistry. 57, 2759-2763. 
[27] Terzic, S., Tripkovic, D., Jovanovic, M. V., Tripkovic, A., \& Kowal, A.(2007). Effect of glassy carbon properties on the electrochemical deposition of platinum nano-catalyst and its activity for methanol oxidation. Journal of Serbial Chemical Society. 72, 165-181.

[28] Ricci, F., Palleschi, G., Yigzaw,Y., Gorton,L., Ruzgas, T., \& Karyakin, A. (2003). Investigation of the effect of different glassy carbon materials on the performance of Prussian blue badsed sensors for hydrogen peroxide. Journal of Electroanalyis. 3, 15.

[29] Farghaly, A. O., Hameed,A. S., \& Nawwas, A. H. (2014). Analytical application using Modern electrochemical techniques. International Journal of Electrochemical Science. 9, 3287-3318.

[30] Creey, Mc. L. R. (1991). Electroanalytical Chemistry. New York editions, Dekker, 17, 12-44. Frank, A. S. (1997). Hand book of instrumental techniques for analytical chemistry. Upper saddle River,prentice-Hall, Inc. 711-714.

[31] Kissinger, P.T., \& Heineman,W.R. (1980). Laboratory techniques in electroanalytical Chemistry, Dekker, New York, in press. 354-359.

[32] Gulaboski, R., \& Pereira, M.C. (2008). Electroanalytical techniques and instrumentation in food analysis. 26, 384-388.

[33] Aristov, N., \& Habekost, A. (2015). Cyclic voltammetry- A versatile electrochemical method investigating electron transfer process. Word Journal of Chemical Education. 3, 115- 119.

[34] Uslu, B., \& Ozakan, A. (2011). Electroanalytical methods for the determination of Pharmaceuticals: A review of recent trends and development. Journal of Analytical Letters. 44, 2644-2702.

[35] Mirceski, V., \& Gulaboski. (2014). Recent achievements in square-wave voltammetry. Journal of Chemistry and Chemical Engineering. 33, 1-12.

[36] Leandro, C.K., Moreira, C. J.,\& Farias, M. A. (2013). Differential pulse voltammetric Studies on lamivudine: An antiretroviral drug. American Journal of Analytical Chemistry. 4, 47-51.

[37] Allen, J. Bard. (1966). Electroanalytical chemistry. Marcel Dekker, Inc. New York, 4- 12 Kong, Y., Chan, Y., Yao,C., Ma, M., \& Chan, Z. (2011). A voltammetric sensor based on electrochemically activated glassy carbon electrode for simultaneous determination of hydroquinone and catechol. Journal of Analytical Methods. 3, 2121.

[38] Mobarake, D.M., Samiee, L., \& Karami, R. (2013). Fabrication and electro catalytic Application of Ni modified electrode toward detection of paracetamol. Journal of Petroleum Science and Techinology.3, 3949.

[39] Zidan, M., Tee, W.T., Abdullah, H.A., \& Zainal, Z. (2011). Electrochemical oxidation of paracetamol mediated by nanoparticles Bismuth oxide modified glassy Carbon electrode. International Journal of Electrochemical Science. 6, 279- 288.

[40] Harvey, D. (2008). Modern analytical chemistry. McGraw-Hill Companies, USA. 668- 685.

Citation: Meselu Eskezia, Dereje Yenealem "Differential Pulse Voltammetric Determination of Paracetamol Using Activated Glassy Carbon Electrode", International Journal of Advanced Research in Chemical Science, 7(6), pp. 24-36. DOI: https:// doi.org/10.20431/2349-0403.0706004

Copyright: (c) 2020 Authors, this is an open-access article distributed under the terms of the Creative Commons Attribution License, which permits unrestricted use, distribution, and reproduction in any medium, provided the original author and source are credited. 